\title{
Prolonged Fever and Exaggerated Hypercoagulopathy in Malaria Vivax Relapse and COVID-19 Co-infection: A Case Report
}

Tri Pudy Asmarawati ( $\sim$ tpasmarawati@fk.unair.ac.id )

Airlangga University Faculty of Medicine: Universitas Airlangga Fakultas Kedokteran https://orcid.org/0000-0001-9869-5098

Okla Sekar Martani

Airlangga University Faculty of Medicine: Universitas Airlangga Fakultas Kedokteran

Bramantono Bramantono

Airlangga University Faculty of Medicine: Universitas Airlangga Fakultas Kedokteran

Muhammad Vitanata Arifianto

Airlangga University Faculty of Medicine: Universitas Airlangga Fakultas Kedokteran

\section{Case report}

Keywords: COVID-19, Malaria, Plasmodium vivax, infectious diseases

Posted Date: September 20th, 2021

DOl: https://doi.org/10.21203/rs.3.rs-907840/v1

License: (9) This work is licensed under a Creative Commons Attribution 4.0 International License. Read Full License 


\section{Abstract}

\section{Background}

Coronavirus disease 2019 (COVID-19) often causes atypical clinical manifestations similar to other infectious diseases. In malaria-endemic areas, the pandemic situation will very likely result in co-infection of COVID-19 and Malaria, although reports to date are still few. Meanwhile, in areas with low malaria prevalence, this disease will be challenging to diagnose because the symptoms closely resemble COVID19.

\section{Case presentation}

A 23-year-old male patient presented to hospital with fever, anosmia, headache, and nausea since one week before. He was diagnosed with COVID-19 and treated for approximately ten days then discharged to continue self-quarantine at home. Two weeks later, he came back to the hospital with fever that was raised intermittently every two days, and was marked by a chilling-fever-sweating cycle. We conducted a laboratory test for malaria and nasopharyngeal swab for SARS CoV-2 PCR which confirmed both of the diagnosis. The laboratory examination showed markedly elevated D-dimer. He was treated with Dihydroartemisinin-Piperaquine (DHP) 4 tablets per day for three days and Primaquine 2 tablets per day for 14 days according to Indonesian national anti-malarial treatment guidelines. After six days of treatment, the patient had no complaints, and the results of laboratory tests had improved. This report describes the key points in considering the differential diagnosis and prompt treatment of malaria infection during the pandemic of COVID-19 in an endemic country to prevent the worse clinical outcomes. COVID-19 and malaria may also cause hypercoagulable state, so a co-infection of those diseases may impact on the prognosis of the disease.

\section{Conclusion}

This case report shows that considering the possibility of a co-infection in COVID-19 patient who presents with fever can prevent delayed treatment that can worsen the disease outcome. Paying more attention to a history of travel to malaria-endemic areas, a history of previous malaria infection, and exploring anamnesis regarding the fever patterns in patients are important points in making a differential diagnosis of malaria infection during the COVID-19 pandemic.

\section{Introduction}

Severe acute respiratory syndrome coronavirus 2 (SARS-CoV-2) is a new strain of coronavirus that started to emerge in December 2019 in Wuhan, China and spread rapidly throughout the world, causing a coronavirus disease (COVID-19) pandemic ${ }^{1}$. The Indonesian government reported that the number of confirmed cases of COVID-19 on August 1, 2021, was 3,409,658, with a total number of 94,119 deaths or a case fatality rate $2.76 \%^{2}$. The SARS-CoV-2 infection causes various clinical manifestations ranging from asymptomatic to a broad spectrum of symptoms, such as mild symptoms of upper respiratory tract 
disorders and life-threatening sepsis. Recent studies have also reported that COVID-19 patients frequently develop hypercoagulopathy and a high prevalence of thromboembolic events ${ }^{3}$. The most common feature in hospitalized COVID-19 patients is fever (70-90\%), impaired sense of smell and taste (64-80\%), dry cough (60-86\%), shortness of breath (53-80\%), fatigue (38\%), nausea/vomiting or diarrhea (15$39 \%)$, and myalgia (15-44\%) ${ }^{4}$. Coagulopathy with abnormally elevated D-dimer levels has been reported in 260 of 560 cases (46.4\%), with the prevalence of $43 \%$ in non-severe patients compared with $60 \%$ in critically ill ICU patients ${ }^{3}$.

Malaria is an infectious disease caused by protozoa of the genus plasmodium, which is transmitted through the bite of the Anopheles mosquito. Malaria infections can cause severe clinical manifestations and death if not promptly diagnosed and treated. There are five species of plasmodium that cause malaria in humans, with the most deaths is caused by Plasmodium falciparum. Plasmodium vivax predominates as a cause of morbidity, while $P$. ovale and $P$. malaria rarely cause severe malaria. Plasmodium knowlesi primarily infects macaques in Southeast Asia, but humans living around these animals can become infected ${ }^{5}$.

Malaria remains a serious global health problem, especially in endemic countries. In 2019, an estimated 229 million malaria cases occurred worldwide, with $3 \%$ of all cases caused by $P$. vivax. $P$. vivax itself is the predominant parasite responsible for $51.7 \%$ of malaria cases in Southeast Asia, including Indonesia 6 . Patients with malaria will usually experience symptoms of paroxysmal fever, fatigue, malaise, and myalgia ${ }^{7}$. A co-infection between COVID-19 and Malaria is rarely reported, and the mechanism is not clearly understood. It is suggested that a co-infection leads to excess proinflammatory responses and pro-coagulant states that might result in more severe manifestations and poor prognosis ${ }^{8}$. Heightened clinical suspicion is needed to diagnose other infections during the COVID-19 pandemic, especially for patients with a traveling history of malaria-endemic areas ${ }^{9}$. In this case report, we found a confirmed COVID-19 patient who was also diagnosed with malaria.

\section{Case Presentation}

A 23-year-old male patient came to the emergency department at Universitas Airlangga Hospital presenting fever, anosmia, headache, and nausea since one week before. He was diagnosed with COVID19 confirmed by the RT-PCR amplification of SARS-CoV-2 virus nucleic acid. The patient was treated for approximately ten days then discharged to continue self-quarantine at home.

Two weeks later, he came back to the hospital with general weakness and fever. The fever did not resolve during his self-quarantine, was raised intermittently every two days, and was marked by a chilling-feversweating cycle. The fever temperature measured was around $39,7^{\circ}-40^{\circ} \mathrm{C}$. The fever improved when the patient took paracetamol, but the fever returned 6 hours later. The fever was accompanied by malaise and muscle pain. The next day the patient was fever-free and able to carry out his daily activities. The physical examination revealed a body temperature of $38^{\circ} \mathrm{C}$, a blood pressure of $112 / 72 \mathrm{mmHg}$, a heart 
rate of $93 \mathrm{bpm}$, a respiratory rate of 20 breaths/minute, and oxygen saturation of $98 \%$ under ambient air. The patient weighs $65 \mathrm{~kg}$ with a height of $170 \mathrm{~cm}\left(\mathrm{BMI} 22.5 \mathrm{~kg} / \mathrm{m}^{2}\right)$. Other physical examinations were normal.

The laboratory results reflected a white blood cell count of $8750 / \mu \mathrm{L}$ with $76.3 \%$ neutrophils, $13.5 \%$ lymphocytes, and $0.6 \%$ eosinophils. Hemoglobin level and platelet count were $12,2 \mathrm{~g} / \mathrm{dL}$ and $231000 / \mu \mathrm{L}$, respectively. CRP and D-dimer levels were $41,51 \mathrm{mg} / \mathrm{L}$ and 9,52 $\mathrm{mg} / \mathrm{L}$, respectively. Serum electrolytes and liver enzymes were within the normal range. Electrocardiography showed normal sinus rhythm and axis. The chest $x$-ray was unremarkable. The RT-PCR amplification of the SARS-CoV-2 virus nucleic acid test from the nasopharyngeal swab was still positive.

From the previous history, he said that he traveled to Timika District, Papua, for office work for the last two years. In May 2021, the patient was infected with $P$. vivax Malaria, with initial symptoms including fever, dizziness, nausea, and muscle pain. The patient was treated until declared fully cured.

We performed a laboratory test for malaria. The rapid malaria test was positive for PAN antigen, and microscopic diagnosis on blood smear revealed Plasmodium vivax on ring form, trophozoite, and gametocyte stage. We diagnosed the patient with confirmed COVID-19 with hypercoagulopathy and malaria vivax relapse based on anamnesis, physical examination, and laboratory results. According to Indonesian National Guidelines for Antimalarial Treatment ${ }^{10}$, he was treated with DihydroartemisininPiperaquine (DHP) 4 tablets per day for three days and Primaquine 2 tablets per day for 14 days. The patient was given an intravenous drip of paracetamol $1000 \mathrm{mg}$ every 8 hours and subcutaneous injection of heparin $5000 \mathrm{IU}$ every 12 hours during treatment. After six days of treatment, the patient had no complaints, and the results of laboratory tests had improved. The patient was discharged from the hospital, continued self-isolation at home, and followed up with the internal medicine outpatient clinic two weeks later. Furthermore, the patient was called later and reported feeling healthy with no complaints at all.

\section{Discussion}

Indonesia is one of the tropical countries in the world still facing a high risk of malaria. Approximately $80 \%$ of cities or districts in Indonesia are endemic to malaria, one of which is Papua. Based on the data from Annual Parasite Incidence (API) in 2019, the number of positive cases of Malaria in Papua is $64.03 \%$ per 1000 population ${ }^{11}$. P. vivax malaria still causes significant morbidity in endemic areas. Reactivation of the dormant stage of hypnozoite can cause $P$. vivax relapse ${ }^{12}$. A single inoculation by a female Anopheles mosquito can be followed by multiple relapses ${ }^{13}$.

Plasmodium vivax is capable of undergoing early and frequent relapses. In addition to blood-stage parasite replication, $P$. vivax has a dormant stage of hypnozoites that can persist in the liver and reactivate to cause relapses weeks or even years later ${ }^{14}$. This reactivation may be triggered by the host's inflammatory response to systemic illnesses or parasitic and bacterial infections, but not viral 
infections ${ }^{15}$. The estimated ratio of $P$. vivax relapses to total infections is $76-90 \%$ in the Papua New Guinea cohort study and $79 \%$ in the Thailand cohort study ${ }^{14}$. Based on the study conducted by Chu et al., $P$. vivax parasitemia recurrences, mainly relapses, occurred in 377 from a total of 644 (59\%) patients treated with artesunate, chloroquine, or chloroquine-primaquine. A history of the previous malaria was more common in patients with recurrences (61\%) than without recurrence (39\%). About $90 \%$ of all $P$. vivax recurrences occurred by week 16 following treatment. Primaquine, as the radical cure with an estimated efficacy of $92 \%$, would reduce the risk of relapses and lessen the significant burden of morbidity caused by $P$. vivax ${ }^{16}$.

The pathophysiology behind the co-infection of COVID-19 with $P$. vivax Malaria remains unclear. It is not known whether SARS-CoV-2 infection reduces the immunity that leads to malaria reactivation or if complications from malaria increase the susceptibility to get COVID-19 ${ }^{17}$. Based on the disease course, this patient was suspected of having reactivation of $P$. vivax infection due to COVID-19 infection. The mechanism that caused the reactivation is still unclear and may be attributed to the cytokine response to COVID-19. There is still a possibility of natural reactivation or reinfection not related to COVID-19 infection that cannot be completely ruled out ${ }^{18}$. The excessive proinflammatory cytokine response generated in coinfection of COVID-19 and Malaria can lead to a worse prognosis ${ }^{19}$.

Early symptoms of SARS-CoV-2 infection such as fever, fatigue, and myalgia, similar to those of malaria, can lead to delayed diagnosis, especially in malaria-endemic areas ${ }^{18}$. In contrast to severe malaria, which is often caused by P. falciparum, where neurological symptoms are predominant and more severe symptoms such as loss of consciousness, signs of focal neurological abnormalities, and severe anaemia can further narrow the diagnosis of malaria. The results of blood tests can also be confusing. Therefore, a diagnostic test for both Malaria and COVID-19 is crucial. The principal diagnosis of malaria to date is the microscopic examination to detect the presence of plasmodium at all stages. However, the sensitivity and specificity of this examination are highly dependent on the examiner's subjectivity. If a microscopy test is not available, a malaria rapid diagnostic test (RDT) can be an alternative to confirm the diagnosis. Another method using a PCR is more sensitive than microscopy, but the results take too long, so it is rarely used ${ }^{20}$. Plasmodium spp and COVID-19 have incubation periods that are not much different. For COVID-19, the incubation period reaches 14 days from exposure with a median value of $4-5$ days, while for malaria, the incubation period varies from 7 to 30 days $^{20}$. It is hence essential to gain a thorough anamnesis in differentiating these two diagnoses.

Hypercoagulopathy is common in COVID-19 patients, especially in those with severe disease ${ }^{21}$. SARSCoV-2 induces tissue factor expression, a primary initiator of the coagulation cascade, by cytokines produced by inflammatory cells. Moreover, SARS-CoV-2 causes endothelial dysfunction through an angiotensin-converting enzyme-2 (ACE-2) receptor expressed on the surface of vascular endothelial cells and induces neutrophil extracellular traps (NETs) release, which activates the coagulation pathways and platelet ${ }^{22}$. Abnormal coagulation parameters such as elevated D-dimer and fibrin degradation product levels and prolonged prothrombin time are related to a poor outcome. The most common manifestations 
of COVID-19 hypercoagulopathy are venous thromboembolism and arterial thrombotic complications, including pulmonary embolism and stroke ${ }^{3}$. COVID-19 patients are at risk for developing disseminated intravascular coagulation (DIC), pulmonary hemorrhage, and thrombosis ${ }^{8}$. Thrombocytopenia associated with a higher risk of severe COVID-19 is suspected to be caused by platelet consumption in the lungs and infected hematopoietic stem cells and megakaryocytes ${ }^{23}$.

Malaria is also strongly associated with a hypercoagulopathy condition through activation of the coagulation cascade triggered by proinflammatory cytokines [e.g., tumor necrosis factor (TNF)-a and interleukin (IL)-6]. The most common coagulopathy condition is microthrombotic complications, besides thrombosis of large vessels, including cerebral venous thrombosis and pulmonary embolism.

Thrombocytopenia is a common finding (60-80\%) that may be due to impaired coagulation, splenomegaly, bone marrow disorders, antibody-mediated platelet destruction, oxidative stress, and platelet aggregation ${ }^{24}$. DIC and bleeding are related to high mortality, occurring only in severe malaria. Tissue factors released from damaged vascular endothelial cells and the lysis of activated platelets contribute to the development of a pro-coagulant state similar to the underlying mechanism in COVID-19. Therefore, Plasmodium spp. and SARS-CoV-2 co-infection could lead to severe coagulopathy and worse outcomes than with either infection alone ${ }^{8}$. In this case, the patient had a high risk of mortality due to hypercoagulopathy condition, which is characterized markedly increased D-dimer levels which was also aggravated by malaria vivax relapse. Regarding this condition, thromboprophylaxis has a crucial role to reduce the risk of thrombotic events.

There were also similar report regarding Malaria and COVID-19 co-infection, as shown in Table 1. The first case report was described by Sardar et al. ${ }^{19}$ in Qatar as a possible $P$. vivax reactivation secondary to COVID-19, similar to the case reports presented by Kishore et al. ${ }^{18}$ in India and Shahid et al. ${ }^{13}$ in Qatar. Ray et al. reported a case of concomitant infection between malaria vivax and COVID-19 in India without suggesting the possibility of $P$. vivax re-activation ${ }^{26}$. However, this report is the first case of malaria vivax and COVID-19 co-infection in Indonesia that discussed the possibility of $P$. vivax relapse related to COVID19 with symptoms of prolonged fever and exaggerated hypercoagulopathy. 
Table 1

A Literature Review of COVID-19 and Plasmodium vivax Co-infection

\begin{tabular}{|c|c|c|c|c|c|c|}
\hline No & Author & Country & $\begin{array}{l}\text { Year of } \\
\text { Publication }\end{array}$ & Age & Clinical Symptoms & $\begin{array}{l}\text { History of } P \text {. vivax } \\
\text { infection }\end{array}$ \\
\hline 1. & $\begin{array}{l}\text { Shahid } \\
\text { Z et al. } \\
13\end{array}$ & Qatar & 2021 & 55 & $\begin{array}{l}\text { Dry cough, high-grade } \\
\text { fever, chills, rigors, } \\
\text { profuse sweating, } \\
\text { lethargy }\end{array}$ & $\begin{array}{l}\text { Documented (1 year } \\
\text { before) }\end{array}$ \\
\hline 2. & $\begin{array}{l}\text { Ray M } \\
\text { et al. }{ }^{26}\end{array}$ & India & 2020 & 67 & $\begin{array}{l}\text { Fever, shortness of } \\
\text { breath }\end{array}$ & Not documented \\
\hline 3. & $\begin{array}{l}\text { Kishore } \\
\text { R et al. } \\
18\end{array}$ & India & 2020 & 10 & $\begin{array}{l}\text { High-grade fever, } \\
\text { chills, rigors, } \\
\text { headache, cold, } \\
\text { cough, abdominal } \\
\text { pain }\end{array}$ & $\begin{array}{l}\text { Documented ( } 6 \text { months } \\
\text { before) }\end{array}$ \\
\hline 4. & $\begin{array}{l}\text { Sardar } \\
\text { S et al. } \\
19\end{array}$ & Qatar & 2020 & 34 & $\begin{array}{l}\text { Fever, myalgia, } \\
\text { vomiting, right upper } \\
\text { quadrant abdominal } \\
\text { pain }\end{array}$ & $\begin{array}{l}\text { Not documented (but } \\
\text { there was a travel history } \\
\text { to Pakistan } 3 \text { months } \\
\text { before) }\end{array}$ \\
\hline
\end{tabular}

Based on WHO recommendations, in terms of facing challenges caused by the COVID-19 pandemic such as the disruption of the malaria rapid test kits supply, the shortage of health workers and personal protective equipment, as well as the limited facilities of the Intensive Care Unit (ICU), the diagnosis of malaria must always be considered in all cases of fever in malaria-endemic countries ${ }^{20}$. In this case, considering the differential diagnosis of malaria infection other than SARS-CoV-2 infection can reduce the risk of morbidity and mortality due to delayed and inappropriate treatment.

Various clinical trials to determine the appropriate COVID-19 therapeutic regimen are still ongoing. The massive use of hydroxychloroquine to treat COVID-19 in Malaria endemic areas will further increase the risk of anti-malarial drug resistance ${ }^{19}$. Artemisinin is a very potent anti-malarial drug and can overcome the problem of resistance to quinolones. Artemisinin is also able to inhibit endocytosis more strongly than chloroquine. Artesunate, a semisynthetic derivative of artemisinin, has lately attracted much attention to be tested as a COVID-19 therapy because of its anti-viral and anti-inflammatory effects through inhibition of Nuclear Factor kappa B (NF-kB) downregulation and protein synthesis in the early stages of viral replication ${ }^{27}$. Further research is required to study the role of artemisinin in treating COVID19 and the prognosis of COVID-19 co-infection with malaria.

\section{Conclusion}

This case report shows that considering the possibility of a secondary infection diagnosis other than COVID-19 in a patient who presents with fever can prevent delayed treatment that can worsen the disease outcome. Paying more attention to a history of travel to malaria-endemic areas, a history of previous malaria infection, and exploring anamnesis regarding the fever patterns in patients are important points 
in making a differential diagnosis of malaria infection during the COVID-19 pandemic.

Hypercoagulopathy is another phenomenon that need further analysis in Malaria and COVID-19 coinfection. Further research is required to study the role of artemisinin in treating COVID-19 and the prognosis of COVID-19 co-infection with malaria.

\section{Abbreviations}

ACE-2: angiotensin-converting enzyme-2; API:annual parasite incidence; COVID-19:coronavirus disease 2019; CRP:C-reactive protein; DHP:dihydroartemisinin-piperaquine; DIC:disseminated intravascular coagulation; ICU:intensive care unit; IL-6:interleukin-6; IU:international unit; LDH:lactate dehydrogenase; NETs:neutrophil extracellular traps; NF-kB:nuclear factor kappa B; RDT:rapid diagnostic test; RT-PCR:realtime polymerase chain reaction; SARS CoV-2:severe acute respiratory syndrome coronavirus-2; SGOT:serum glutamic oxaloacetic transaminase; SGPT:serum glutamic pyruvic transaminase; TNFa:tumor necrosis factor-a

\section{Declarations}

\section{Ethics approval and consent to participate}

Not applicable

\section{Consent for publication}

Written informed consent for publication of their clinical details and/or clinical images was obtained from the patient. A copy of the consent form is available for review by the Editor of this journal.

\section{Availability of data and materials}

Not applicable

\section{Competing interests}

The authors declare that they have no competing interests

\section{Funding}

Not applicable

\section{Authors' contributions}

TP and OS contributed to the conception and manuscript preparation. BB and MV contributed to the literature search. All author have read and approved the submitted version.

\section{Acknowledgements}




\section{References}

1. Wiersinga WJ, Rhodes A, Cheng AC, Peacock SJ, Prescott HC. Pathophysiology. Transmission, Diagnosis, and Treatment of Coronavirus Disease 2019 (COVID-19): A Review. JAMA. 2020;324(8):782-93. doi:10.1001/jama.2020.12839.

2. Gugus Tugas Percepatan Penanganan COVID-19. Peta Sebaran COVID-19 Indonesia 2021 [cited 20212 August 2021]. Available from: https://covid19.go.id/.

3. Iba T, Levy JH, Levi M, Connors JM, Thachil J. Coagulopathy of Coronavirus Disease 2019. Crit Care Med. 2020;48(9):1358-64. doi:10.1097/ccm.0000000000004458.

4. Guan WJ, Ni ZY, Hu Y, Liang WH, Ou CQ, He JX, et al. Clinical Characteristics of Coronavirus Disease 2019 in China. N Engl J Med. 2020;382(18):1708-20. doi:10.1056/NEJMoa2002032.

5. Moxon CA, Gibbins MP, McGuinness D, Milner DA Jr, Marti M. New Insights into Malaria Pathogenesis. Annu Rev Pathol. 2020;15:315-43. doi:10.1146/annurev-pathmechdis-012419032640.

6. WHO. World Health Organization. World Malaria Report 2020: 20 years of global progress and challenges. Geneva: World Health Organization; 2020. Available from: https://www.who.int/publications/i/item/9789240015791.

7. Cowman AF, Healer J, Marapana D, Marsh K. Malaria. Biology Disease Cell. 2016;167(3):610-24. doi:10.1016/j.cell.2016.07.055.

8. Gutman JR, Lucchi NW, Cantey PT, Steinhardt LC, Samuels AM, Kamb ML, et al. Malaria and Parasitic Neglected Tropical Diseases: Potential Syndemics with COVID-19? Am J Trop Med Hyg. 2020;103(2):572-7. doi:10.4269/ajtmh.20-0516.

9. Correia MJ, Frade L, Guerreiro R, Araujo I, Baptista T, Fonseca C, et al. A Patient with Severe Malaria and COVID-19: How Do You Tell the Difference between These Infections? Eur J Case Rep Intern Med. 2020;7(12):002007. doi:10.12890/2020_002007.

10. Kemenkes. Kementerian Kesehatan RI. Buku Saku Tatalaksana Kasus Malaria. Jakarta: Kementerian Kesehatan Rl; 2019.

11. Kemenkes. Kementerian Kesehatan RI. Profil Kesehatan Indonesia Tahun 2019. Jakarta: Kementerian Kesehatan Rl; 2020.

12. Dayananda KK, Achur RN, Gowda DC. Epidemiology, drug resistance, and pathophysiology of Plasmodium vivax malaria. J Vector Borne Dis. 2018;55(1):1-8. doi:10.4103/0972-9062.234620.

13. Shahid Z, Karim N, Shahid F, Yousaf Z. COVID-19 Associated Imported Plasmodium vivax Malaria Relapse: First Reported Case and Literature Review. Res Rep Trop Med. 2021;12:77-80. doi:10.2147/rrtm.S292157.

14. White MT, Karl S, Koepfli C, Longley RJ, Hofmann NE, Wampfler R, et al. Plasmodium vivax and Plasmodium falciparum infection dynamics: re-infections, recrudescences and relapses. Malar J. 
2018;17(1):170. doi:10.1186/s12936-018-2318-1.

15. Shanks GD, White NJ. The activation of vivax malaria hypnozoites by infectious diseases. Lancet Infect Dis. 2013;13(10):900-6. doi:10.1016/s1473-3099(13)70095-1.

16. Chu CS, Phyo AP, Lwin KM, Win HH, San T, Aung AA, et al. Comparison of the Cumulative Efficacy and Safety of Chloroquine, Artesunate, and Chloroquine-Primaquine in Plasmodium vivax Malaria. Clin Infect Dis. 2018;67(10):1543-9. doi:10.1093/cid/ciy319.

17. Eid MM. Co-Infection with COVID-19 and Malaria in a Young Man. Dubai Medical Journal. 2021;4:13. doi:10.1159/000514254.

18. Kishore R, Dhakad S, Arif N, Dar L, Mirdha BR, Aggarwal R, et al. COVID-19: Possible Cause of Induction of Relapse of Plasmodium vivax Infection. Indian J Pediatr. 2020;87(9):751-2. doi:10.1007/s12098-020-03441-6.

19. Sardar S, Sharma R, Alyamani TYM, Aboukamar M. COVID-19 and Plasmodium vivax malaria coinfection. IDCases. 2020;21:e00879. doi:10.1016/j.idcr.2020.e00879.

20. Di Gennaro F, Marotta C, Locantore P, Pizzol D, Putoto G. Malaria and COVID-19: Common and Different Findings. Trop Med Infect Dis. 2020;5(3). doi:10.3390/tropicalmed5030141.

21. Terpos E, Ntanasis-Stathopoulos I, Elalamy I, Kastritis E, Sergentanis TN, Politou M, et al. Hematological findings and complications of COVID-19. Am J Hematol. 2020;95(7):834-47. doi:10.1002/ajh.25829.

22. Mori H, Ohkawara $H$, Togawa R, Rikimaru M, Shibata $Y$, Ikezoe T. Diagnosis and treatment of disseminated intravascular coagulation in COVID-19 patients: a scoping review. Int J Hematol. 2021;113(3):320-9. doi:10.1007/s12185-021-03084-z.

23. Lin J, Yan H, Chen $\mathrm{H}, \mathrm{He} \mathrm{C}$, Lin C, He H, et al. COVID-19 and coagulation dysfunction in adults: A systematic review and meta-analysis. J Med Virol. 2021;93(2):934-44. doi:10.1002/jmv.26346.

24. Autino B, Corbett Y, Castelli F, Taramelli D. Pathogenesis of malaria in tissues and blood. Mediterr J Hematol Infect Dis. 2012;4(1):e2012061. doi:10.4084/mjhid.2012.061.

25. WHO. World Health Organization. Guidelines for Malaria. Geneva: World Health Organization; 2021. Available from: https://www.who.int/publications/i/item/guidelines-for-malaria.

26. Ray M, Vazifdar A, Shivaprakash S. Co-infection with Malaria and Coronavirus Disease-2019. J Glob Infect Dis. 2020;12(3):162-3. doi:10.4103/jgid.jgid_160_20.

27. Uzun T, Toptas O. Artesunate: could be an alternative drug to chloroquine in COVID-19 treatment? Chin Med. 2020;15:54. doi:10.1186/s13020-020-00336-8. 